\title{
Heating of heavy oil by circulating hot water in closed double casing in ultra-deep wells
}

\author{
Lin Riyi*, Wang Fangzheng and Wang Xinwei \\ College of Pipeline and Civil Engineering, China University of Petroleum (East), Qingdao, Shandong 266580, China \\ (C) China University of Petroleum (Beijing) and Springer-Verlag Berlin Heidelberg 2012
}

\begin{abstract}
In heavy oil production, the loss of energy to ambient surroundings decreases the temperature of the heavy oil flowing upwards in a vertical wellbore, which increases the oil viscosity and the oil may not flow normally in the wellbore. Therefore, it is necessary to lower the heavy oil viscosity by heating methods to allow it to be lifted easily. Heating of heavy oil in an oil well is achieved by circulating hot water in annuli in the well (tubing-casing annulus, casing-casing annulus). In this paper, based on heat transfer principles and fluid flow theory, a model is developed for produced fluids and hot water flowing in a vertical wellbore. The temperature and pressure of produced fluids and hot water in the wellbore are calculated and the effect of hot water on heavy oil temperature is analyzed. Calculated results show that the hot water circulating in the annuli may effectively heat the heavy oil in the tubing, so as to significantly reduce both oil viscosity and resistance to oil flow.
\end{abstract}

Key words: Heavy oil, double casing, hot water injection, viscosity reduction

\section{Introduction}

Heavy oil resources are mainly concentrated in the USA, Canada, Venezuela and China. The predicted reserves of heavy oil in China are above $8 \times 10^{9}$ tonnes, which are mainly distributed in the Songliao, Bohai Bay and Junggar basins. The production of heavy oil has increased in recent years in China (Zhang and Wan, 2002; Wan, 2008). Some heavy oil may easily flow into the bottom hole under reservoir conditions, although it is comparatively viscous. However, when the oil is lifted upwards in the wellbore. Its viscosity increases rapidly and the oil gradually loses its fluidity due to a decrease in wellbore temperature and some water coming out of solution from the oil. Therefore, the heavy oil may not flow and be lifted to the surface.

In heavy oil production, heating methods (electric heating and hot fluid circulation) or injecting chemical agents or thin oil to the wellbore are used to lower the viscosity of heavy oil to allow the oil to be lifted more easily (Chen et al, 2010). Hot fluid circulation (Li et al, 2010; Lin et al, 2010) is mainly applied to shallow heavy oil of high freezing point and high viscosity. The circulation loops can be divided into two types, namely open and closed loops. Open hot fluid circulation is also divided into positive and reverse circulation, the hot and cold fluids will mix and exchange heat with each other in the channel consisted of tubing and annulus. Closed hot fluid circulation in two annuli (tubing-casing annulus, casing-

*Corresponding author. email: linry@upc.edu.cn Received February 1, 2012 casing annulus) is studied, and fluid flow in this loop is analyzed and a heat transfer mathematical model is presented to optimize fluid circulation parameters and to improve energy utilization efficiency (Chiu and Thakur, 1991; Jurak and Prnić, 2005).

\section{Physical model of hot water in a closed loop}

A schematic of wellbore structure is shown in Fig. 1. The hot water is injected into the inner annulus between the inner casing and the oil tubing and returns to the surface through the outer annulus between the inner casing and the outer casing, and the oil is produced from the oil tubing. A conceptual model is built and the assumptions are:

1) The injection rate of hot water, pressure and flow rate remain unchanged.

2) A casing packer is installed between the tubing and the outer casing at some distance above the bottom hole to seal the annuli.

3) The heat transfer from the well to the outer edge of cement is regarded as steady and one dimensional (Ramey, 1962; Yang and Tao, 2006).

4) Changes in the formation thermal conductivity in the depth direction are ignored, and the thermal conductivity is taken as a constant.

Based on the above assumptions, the radial heat transfer includes two parts: steady state heat transfer from the oil tubing to the edge of the cement sheath and unsteady-state (transient) heat transfer from the cement to the formation. 


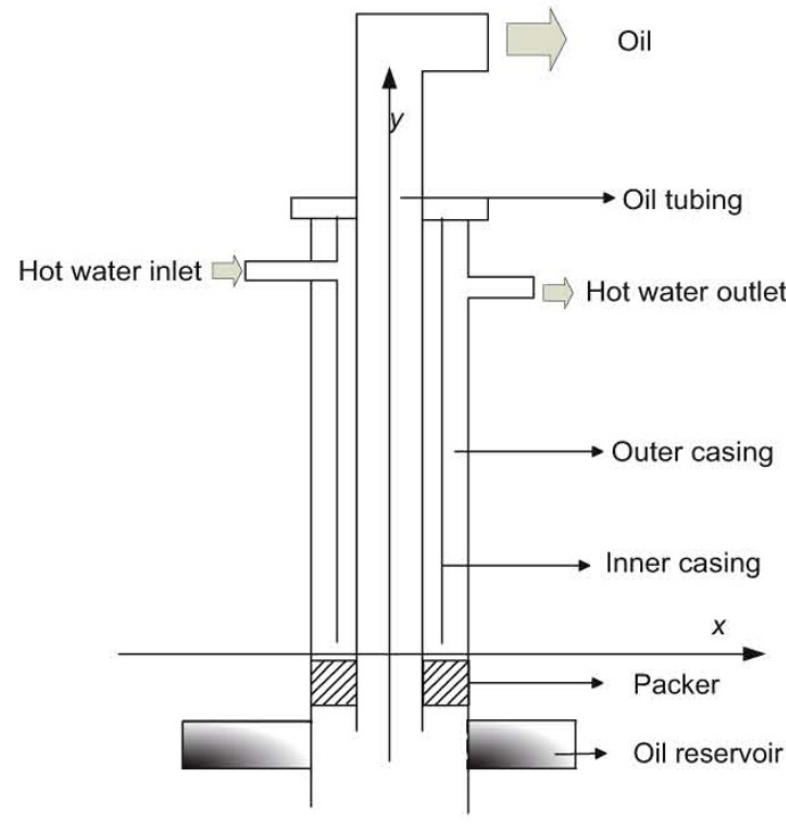

Fig. 1 Schematic of the pipe structure

\section{Mathematical model of fluids within the wellbore}

\subsection{Heat transfer calculation model of wellbore fluids}

In closed hot fluid circulation (Ren et al, 2001), heat is transferred from the injected hot fluid to the heavy oil through the tubing wall, and the viscosity of the oil decreases. The high temperature fluid is injected at the wellhead, and heat is mainly transferred from the hot fluid to the oil in some depth in the well. Because the flow path of the injected hot fluid is relatively long, the hot fluid temperature declines down in the inner annulus due to continuous heat loss. The heating depth of oil tubing is generally deeper than the position where the oil temperature is equal to the wax precipitation point, which can reduce the oil viscosity effectively(Alves et al, 1992; Danilović et al, 2010). Therefore, a mathematical model using a Cartesian coordinate system is established (Fig. 1), and the wellbore temperature model is:

$$
\left\{\begin{array}{l}
\frac{\mathrm{d} \theta}{\mathrm{d} z}=\frac{k_{11}(t-\theta)}{q_{\mathrm{m} 1} c_{\mathrm{p} 1}} \\
\frac{\mathrm{d} t}{\mathrm{~d} z}=\frac{k_{12}(t-T)+k_{11}(t-\theta)}{q_{\mathrm{m} 2} c_{\mathrm{p} 2}} \\
\frac{\mathrm{d} T}{\mathrm{~d} z}=\frac{k_{12}(t-T)-k_{13}\left[T-\left(t_{\mathrm{f} 0}-m z\right)\right]}{q_{\mathrm{m} 3} c_{\mathrm{p} 3}} \\
\theta=\theta_{0}, z=z_{1} \\
t=200, z=z_{0} ; \\
t=T, z=z_{1}
\end{array}\right.
$$

where $\theta$ is the temperature of oil in the tubing, ${ }^{\circ} \mathrm{C} ; t$ and $T$ are the temperatures of the hot fluid in the inner annulus and the outer annulus, ${ }^{\circ} \mathrm{C}$; $k_{11}$ is the heat transfer coefficient between the circulating hot fluid in the inner annulus and the oil in the tubing, $\mathrm{W} /\left(\mathrm{m} \cdot{ }^{\circ} \mathrm{C}\right) ; k_{12}$ is the heat transfer coefficient between the circulating hot fluid in the inner and outer annuli, $\mathrm{W} /\left(\mathrm{m} \cdot{ }^{\circ} \mathrm{C}\right) ; k_{13}$ is the heat transfer coefficient between the circulating hot fluid the in the outer annulus and the formation, $\mathrm{W} /\left(\mathrm{m}^{\circ}{ }^{\circ} \mathrm{C}\right) ; q_{\mathrm{m} 1}$ is the oil mass flow rate, $\mathrm{kg} /$ $\mathrm{s} ; q_{\mathrm{m} 2}$ and $q_{\mathrm{m} 3}$ are the mass flow rates of the hot fluid in the inner and outer annuli, $\mathrm{kg} / \mathrm{s} ; c_{\mathrm{p} 1}$ is the specific heat capacity of heavy oil, $\mathrm{kJ} /\left(\mathrm{kg} \cdot{ }^{\circ} \mathrm{C}\right) ; c_{\mathrm{p} 2}$ and $c_{\mathrm{p} 3}$ are the specific heat of the hot fluid in the inner and outer annuli, $\mathrm{kJ} /\left(\mathrm{kg} \cdot{ }^{\circ} \mathrm{C}\right) ; t_{\mathrm{fo}}$ is the original bottomhole temperature, ${ }^{\circ} \mathrm{C} ; m$ is the formation temperature gradient, $m=0.02{ }^{\circ} \mathrm{C} / \mathrm{m} ; z$ is formation depth, $\mathrm{m}$.

\subsection{Pressure model of wellbore fluids}

The pressure gradient is caused by friction, gravity and acceleration (Beggs and Brill, 1973; Zhang, 2006).

$$
-\frac{\mathrm{d} p}{\mathrm{~d} z}=\frac{f \rho u^{2}}{2 D}+\rho g \sin \alpha+\frac{m_{1}}{A} \frac{\mathrm{d} v}{\mathrm{~d} z}
$$

where $p$ is pressure, $\mathrm{MPa} ; \rho$ is fluid density, $\mathrm{kg} / \mathrm{m}^{3} ; f$ is friction coefficient; $D$ is the equivalent diameter of the pipe, $\mathrm{m} ; u$ is flow rate, $\mathrm{m} / \mathrm{s} ; \alpha$ is deviation angle, ${ }^{\circ} ; g$ is the acceleration of gravity, $\mathrm{m} / \mathrm{s}^{2} ; m_{1} \mathrm{~d} v$ is unit momentum, $\mathrm{kg} \cdot \mathrm{m} / \mathrm{s} ; A$ is the pipe cross-sectional area, $\mathrm{m}^{2}$.

The acceleration pressure drop is meaningful only when the flow state of the fluid is mist flow or the flow acceleration varies greatly. In this paper, we focus on a single-phase fluid, such as water or oil. The flow rate and the pipe diameter are constant and the fluid velocity changes little. Therefore, the pressure loss (pressure gradient) due to acceleration is not high, so it can be safely neglected (Zhang, 2006; Chen, 1989).

In vertical wells, $\alpha=90^{\circ}, \sin \alpha=1$.

When the flow resistance and gravity are in the same direction, the pressure gradient is expressed as:

$$
-\frac{\mathrm{d} p}{\mathrm{~d} z}=\frac{f}{D} \frac{\rho u^{2}}{2}+\rho g
$$

When the flow resistance and gravity are in the opposite direction, the pressure gradient is expressed as:

$$
-\frac{\mathrm{d} p}{\mathrm{~d} z}=-\frac{f}{D} \frac{\rho u^{2}}{2}+\rho g
$$

where $\rho, u, g$, and $D$ are known.

The friction coefficient $f$, related to the flow pattern, can be calculated by the friction coefficient formula of different flow patterns according to Reynolds number Re (Yang and Tao, 2006).

\section{Model and results}

In order to calculate temperature and pressure distributions of wellbore fluids and to investigate the impact of various factors, the wellbore is divided into several unit bodies. In each body the temperature and pressure are regarded as 
uniform and the heat transfer and flow characteristics of the two fluids (oil and hot fluid) in the wellbore of each unit body are investigated.

\subsection{Distribution of the wellbore fluid pressure}

The basic data used in the model taken from Well $\mathrm{S} 94 \mathrm{CH}$, located in the Tahe Oil Field, are listed in Table 1. The well has a tubing, a double casing and a bottom packer. The double casing was laid down to a depth of 3,500 $\mathrm{m}$, where the formation temperature was $112{ }^{\circ} \mathrm{C}$.

Table 1 Basic data used in a sample run

\begin{tabular}{|c|c|}
\hline Parameter & Value \\
\hline Reservoir temperature, ${ }^{\circ} \mathrm{C}$ & 131.6 \\
\hline Reservoir pressure, $\mathrm{MPa}$ & 60 \\
\hline Well depth, m & 5830 \\
\hline \multicolumn{2}{|l|}{ Pipe size } \\
\hline Oil tubing diameter, inch & 3.5 \\
\hline Inner casing diameter, inch & 7.0 \\
\hline Outer casing diameter, inch & 9.625 \\
\hline Circulation rate of hot water, $t / d$ & 150 \\
\hline Wellhead pressure, $\mathrm{MPa}$ & 5 \\
\hline Injection temperature, ${ }^{\circ} \mathrm{C}$ & 200 \\
\hline Oil production, $\mathrm{t} / \mathrm{d}$ & 168 \\
\hline Water cut, $\%$ & 0 \\
\hline Oil viscosity at $50^{\circ} \mathrm{C}, \mathrm{Pa} \cdot \mathrm{s}$ & 13200 \\
\hline
\end{tabular}

When hot water flows into the inner annulus, the flow resistance and gravity are in the opposite direction. So Eq. (4) is used to calculate the pressure gradient and the friction coefficient can be expressed as follows:

$$
f=\frac{0.316}{R e^{0.25}}
$$

with

$$
\operatorname{Re}=\frac{\rho u D}{\mu}
$$

where $\mu$ is the dynamic viscosity, $\mathrm{Pa} \cdot \mathrm{s}$.

Substituting Eqs. (5) and (6) into Eq. (4) yields

$$
-\frac{\mathrm{d} p}{\mathrm{~d} z}=-0.158 \frac{\mu^{0.25} \rho^{0.75} u^{1.75}}{D^{1.25}}+\rho g
$$

where $\rho, u, g, D$, and $\mu$ are known.

The pressure change per unit length is expressed as follows:

$$
\begin{aligned}
& \Delta p=-\frac{\mathrm{d} p}{\mathrm{~d} z} \\
& p_{x+1}=p_{x}+\Delta p
\end{aligned}
$$

Therefore, we can obtain the pressure distribution in the inner and outer annuli. Fig. 2 shows the fluid pressure distributions at different well depths. It can be seen that the injection pressure of circulating water is $5 \mathrm{MPa}$ and the back pressure is $3.68 \mathrm{MPa}$.

In Fig. 2, the outlet pressure (back pressure) of the outer annulus is about $3 \mathrm{MPa}$, which exceeds the minimum pressure required to circulate the hot water in the annuli. If there is adequate lifting force, reducing the injection pressure may decrease operating costs. If considering economic benefits, the inlet pressure of the inner casing can be decreased to a minimum value, while still allowing the hot fluid to circulate normally.

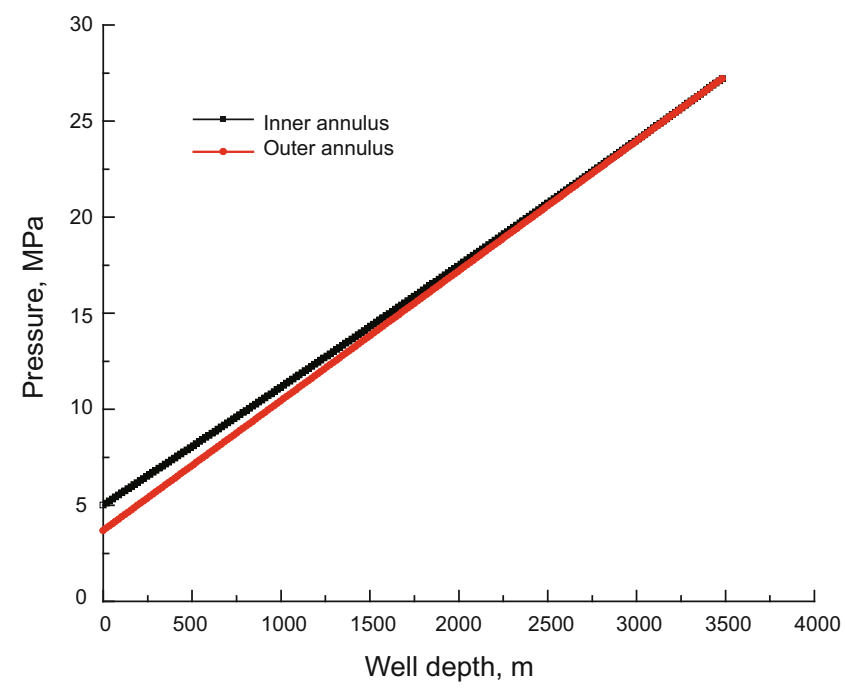

Fig. 2 The fluid pressure distributions down the wellbore

\subsection{Wellbore temperature distribution}

The temperature distribution down the wellbore is shown in Fig. 3. This indicates that the lowest temperature of oil in the wellbore is about $60{ }^{\circ} \mathrm{C}$, and oil still can flow in the tubing. This is because wax precipitation does not occur at 60 ${ }^{\circ} \mathrm{C}$ (Ren et al, 2001). We can take some measures to increase the oil temperature to ensure the fluidity of crude oil.

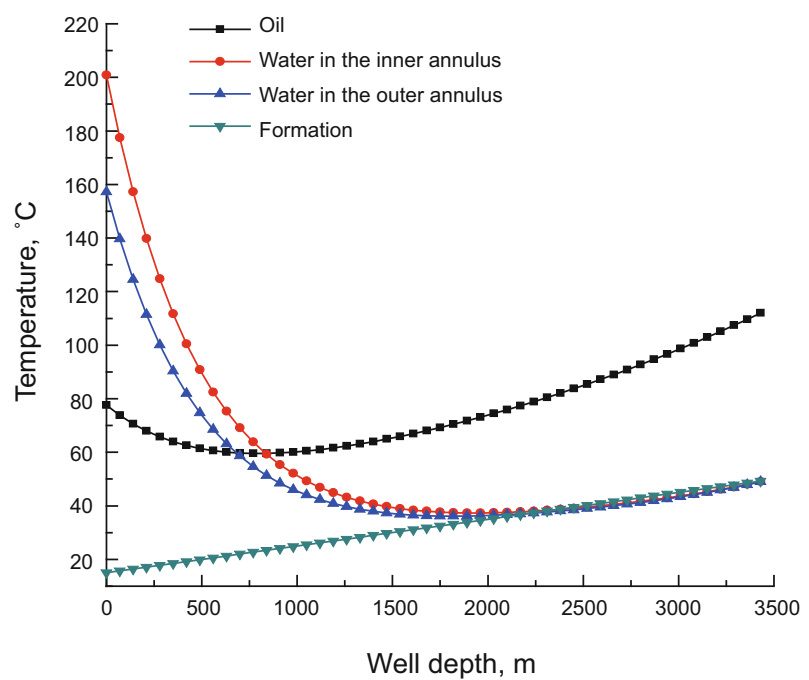

Fig. 3 The temperature distribution of the system 
An approximately exponential relationship between oil viscosity and temperature is indicated (Brown, 1987; Feng and Guo, 2006), and the temperature is the main factor affecting viscosity. Therefore, analysis of temperature distribution in the wellbore is important for understanding the oil viscosity profile in the wellbore (Manabe et al, 2003; Prats, 2002).

Calculated results in Fig. 3 show temperature profiles of hot water and crude oil in the wellbore. The initial oil temperature at the wellbore bottom is relatively high, and the oil temperature decreases when it is lifted from the bottom because the heat is transferred from the oil to the circulating water in the deep section of the inner annulus. There is a critical depth at which the oil temperature reaches a minimum, above which heat is transferred from the hot water to the oil and then the oil temperature rises. On the other hand, the temperature of the hot water declines rapidly from the wellhead until the water temperature is equal to the oil temperature, then slowly due to heat transfer from hightemperature oil in the tubing.

If the oil temperature at some depth which the water temperature is equal to the oil temperature is much higher than the wax appearance point, we can set the double casing to a location at or slightly below the depth (not to the bottom of the wellbore) or reduce the inlet temperature of the hot water to reduce material costs and energy consumption.

\subsection{The effect of water flow rate on oil temperature}

Fig. 4 indicates the effect of the flow rate of the hot water circulating in annuli on the oil temperature. The minimum oil temperature rises as the hot water flow rate increases, and the maximum viscosity of the oil reduces. The water injection pressure at the wellhead has to be increased for an increased flow rate. This means that a high injection pressure is required to pump hot water into the inner annulus for a high flow rate of $8.33 \mathrm{t} / \mathrm{h}$. Generally, the rated pressure of a circulating pump is limited, and high pressures will increase costs, so the ideal flow rate of the hot water should be determined according to the rated pressure of the pump and the desired minimum temperature of the oil in the wellbore.

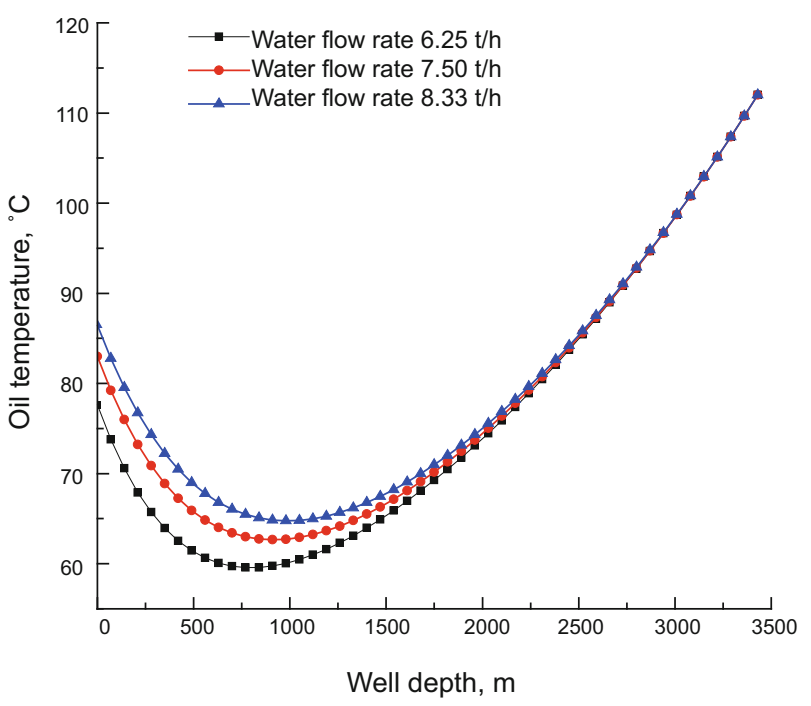

Fig. 4 Oil temperature distributions at different hot water flow rates

\subsection{The effect of water temperature on oil temperature}

The effect of the temperature of the circulating hot water on the oil temperature is investigated. Fig. 5 shows that the hot water temperature has a significant effect on the oil temperature. The hot water temperature and the setting depth of the double casing should be optimized to obtain economic benefits. In Fig. 5, the temperature of oil at a depth of 0-910 $\mathrm{m}$ increases significantly when the hot water temperature is $284{ }^{\circ} \mathrm{C}$. However, the injection of high-temperature water may place a heavy burden on the boiler and a lot of heat loss. The impact of hot water temperature on oil temperature decreases gradually with increasing well depth. Therefore, the maximum temperature of hot water should be lower than the rated temperature of the hot water boiler, and the ideal temperature of hot water will save energy.

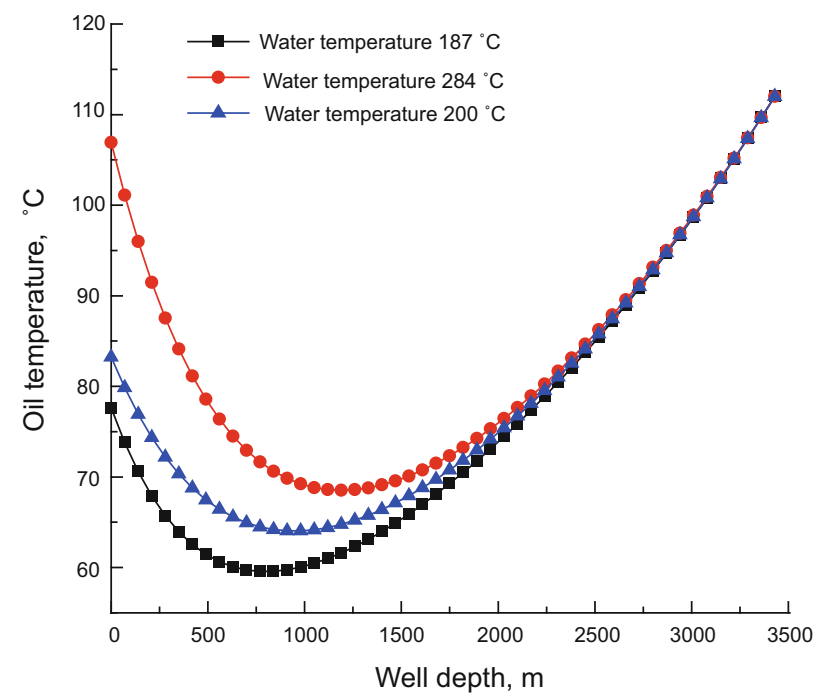

Fig. 5 Oil temperature distribution at different hot water temperatures

\subsection{The effect of crude oil production rate on oil temperature}

A change of oil production rate alters the heat transfer between oil and water. As well, a high-power lift pump is required to increase the production rate, which is likely to lead to higher energy consumption. The oil temperature profiles along the wellbore at different oil production rates are shown in Fig. 6.

The influence of the oil production rate on the oil temperature is not as apparent as that of injection temperature of the hot water. The flow characteristics of the heavy oil become complex and the energy consumption of the pumping unit increases rapidly as the oil production rate increases.

\section{Conclusions}

1) Because of the transfer of heat from the circulating hot water and insulation of the casing annulus, the heavy oil flowing upwards in the tubing maintains a high temperature. This indicates that hot water circulating in a closed double casing will effectively reduce the viscosity of heavy oil and make the oil flow more easily to the surface from the bottom 


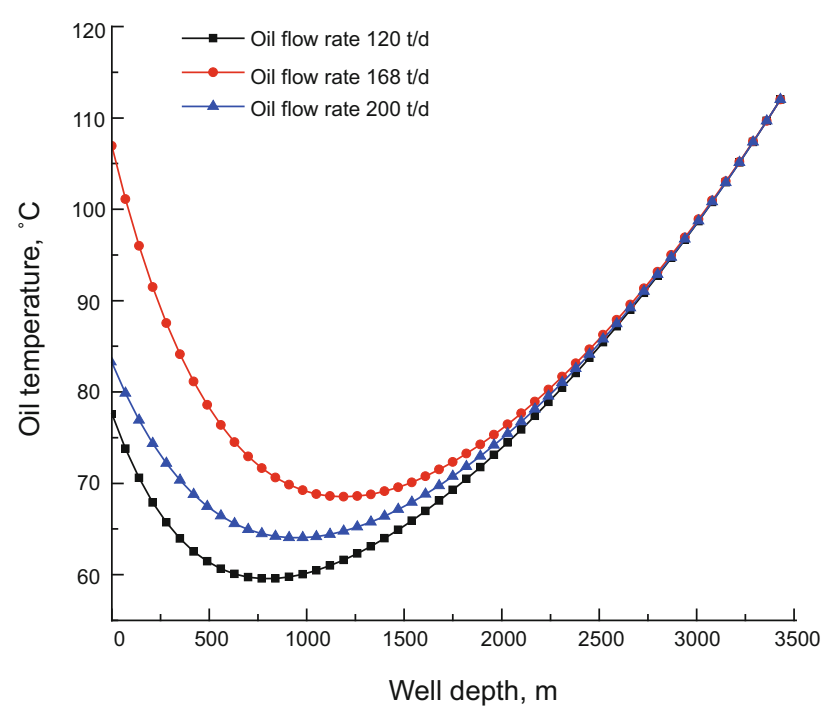

Fig. 6 Oil temperature distributions at different oil production rates

hole. This technology is already used to reduce heavy oil viscosity in ultra-deep wells.

2) The injection temperature of the hot water is the most important factor affecting the temperature of the crude oil, followed by the hot water flow rate. In order to reduce production costs, we can use the model proposed in this paper to optimize production parameters.

\section{Acknowledgements}

This work was supported by the Fundamental Research Funds for the Central Universities (No. 27R1015025A), the Natural Science Foundation of Shandong Province, China (Grant No. 05J10150300). A very special acknowledgement is made to the editors and referees whose constructive criticism has improved this paper.

\section{References}

Alves I N, Alhantl F J S and Shoham O. A unified model for predicting flowing temperature distribution in wellbores and pipelines. SPE Production Engineering. 1992. 7(4): 363-367 (paper SPE 20632)

Beggs H D and Brill J P. A study of two-phase flow in inclined pipes. Journal of Petrology Technology. 1973. 25(5): 607-617
Brown K E. The Technology of Artificial Lift Methods. Pennwell Books, Tulsa, Oklahoma.1984

Chen C G, Guo J X, Wang H Y, et al. Synthesis and evaluation of an oilsoluble viscosity reducer for heavy oil. Petroleum Science. 2010 7(4): 536-540

Chen J L. Petroleum Gas-liquid Two-Phase Pipe Flow. Beijing: Petroleum Industry Press. 1989. 99-105 (in Chinese)

Chiu K and Thakur S C. Modeling of wellbore heat losses in directional wells under changing injection conditions. SPE Annual Technical Conference and Exhibition, 6-9 October 1991, Dallas, Texas (paper SPE 22870)

Danilović D S, Karović-Maričić V D and Čokorilo V B. Solving paraffin deposition problem in tubing by heating cable application. Thermal Science. 2010. 14(1):247-253

Feng S C and Guo K C. Oil and Gas Production and Processing. Dongying: University of Petroleum Press. 2006. 87-90 (in Chinese)

Jurak M and Prnić Z. Heating of oil well by hot water circulation. Proceedings of the Conference on Applied Mathematics and Scientific Computing. 2005. 13(2): 235-244

Li S Y, Li Z M, Li B F, et al. Modeling of lifting heavy oil assisted by enclosed thermal fluid circulation in hollow rod. Journal of Petroleum Science and Engineering. 2010. 75(1-2): 135-142

Lin R Y, Liang J G, Yang D W, et al. Viscosity reduction technology by closed hot water circulation in hollow sucker rods. Journal of China University of Petroleum (Edition of Natural Science). 2010. 34(3): 104-108 (in Chinese)

Manabe R, Wang Q and Zhang, H Q. A mechanistic heat-transfer model for vertical two-phase flow. SPE Annual Technical Conference and Exhibition, 5-8 Oct 2003, Denver, Colorado (paper SPE 84226)

Prats M. The effect of heat transfer between nearby layers on the volume of steam zones. SPE Journal. 2002. 7(2): 221-230 (paper SPE 71869)

Ramey H J. Wellbore heat transmission. Journal of Petroleum Technology. 1962.14 (4): 427-435

Ren Y, Liang J G and Yang S H. The Theory and Practice of Heavy and High Pour Point Oil Heat Production. Beijing: Petroleum Industry Press. 2001. 1-13 (in Chinese)

Wan R P. Petroleum Engineering Manual. Beijing: Petroleum Industry Press. 2008. 105-179 (in Chinese)

Yang S M and Tao W Q. Heat Transfer (4th Edition). Beijing: Higher Education Press. 2006. 41-56 (in Chinese)

Zhang Q and Wan R P. Project Design of Oil Production Engineering. Beijing: Petroleum Industry Press. 2002. 8-10 (in Chinese)

Zhang Q. Principle and Design of Oil Production Engineering. Dongying: University of Petroleum Press. 2006. 141-146 (in Chinese)

(Edited by Sun Yanhua) 